\title{
Cost-Effectiveness Analysis of a PVGS on the Electrical Power Supply of a Small Island
}

\author{
Cheng-Ting Hsu, Roman Korimara, and Tsun-Jen Cheng \\ Department of Electrical Engineering, Southern Taiwan University of Science and Technology, Tainan 710, Taiwan \\ Correspondence should be addressed to Tsun-Jen Cheng; chengtj@mail.stust.edu.tw
}

Received 6 April 2014; Accepted 21 May 2014; Published 12 June 2014

Academic Editor: Yen-Lin Chen

Copyright (C) 2014 Cheng-Ting Hsu et al. This is an open access article distributed under the Creative Commons Attribution License, which permits unrestricted use, distribution, and reproduction in any medium, provided the original work is properly cited.

\begin{abstract}
This paper presents a feasibility study of a large simulated stadium-scale photovoltaic generation system (PVGS) on a small island. Both the PVGS contribution to the energy demand on the island and its financial analysis were analysed in this study. The maximum allowable PVGS installation capacity is obtained by executing load flow analysis without violating the voltage magnitude and voltage variation ratio limits. However, the estimated power generation of PVGS is applied to know its impact on the power system according to the hourly solar irradiation and temperature. After that, the cost-benefit analysis of payback years (PBY) and net present value (NPV) method is derived considering the cash flow from utilities annual fuel and loss saving, the operation and maintenance (O\&M) cost, and the capital investment cost. The power network in Kiribati (PUB DNST) is selected for study in this paper. The simulation results are very valuable and can be applied to the other small islands for reducing the usage of fossil fuel and greenhouse gas emissions.
\end{abstract}

\section{Introduction}

With the abundant solar and wind energy in small island countries, over the last few years a number of influences have combined to lead to the increased interest in renewable distribution generation such as wind and solar. Environmental impact is a major factor in the consideration of this electrical power scheme, and there is generally accepted concern over greenhouse gases emission from thermal power plants. Reference [1] shows that developing various renewable energy resources is essential for achieving sustainable environment. In Kiribati priorities of the government in the energy sector are currently focused on locating additional finance for the expansion of rural electrification and on reducing cost of fuel imports. Due to the increasing cost of import fuel for the utility power generation causing saturation to the utility sector's overall operation cost, making it difficult for them to gain profit, the government of the day have no choice but to subsidize the utility sector annually to avoid power shutdown [2]. Fortunately, having the favorable position on the equator, the country has big advantage of developing application of several types of renewable energy resources such as tidal energy, wind energy, and solar energy. With the population of only more than one hundred thousand in a wide total area of $811 \mathrm{~km}$ in Kiribati, a photovoltaic (PV) panel may be a good solution for fulfilling the energy requirement and protecting the environment. Thanks to World Bank that provided the finances, the first ever large photovoltaic plant with a total capacity of $500 \mathrm{kWp}$ was installed in Kiribati [3].

For the engineering project of a large scale PVGS, the economic analysis should be performed to evaluate the profitability to ensure the investment cost can be recovered over the life cycle. The classical profitability analysis has been performed on PVGS in $[4,5]$. A cost analysis of PV grid connection for several European countries is presented in [6]. It is concluded that the main factors affecting the PVGS deployment are the initial capital cost of the system, the feedin tariff, and the capital cost subsidization rate. Reference [7] presented the economic aspects of a hybrid system with solar energy and wind energy production. Two economic indices of the NPV and the PBY are applied for the financial analysis for the PV system projects by considering the cash inflows 
and the life-cycle expenses in $[8,9]$. The parameters of NPV and payback period are used to determine the profitability of PV installation by including the reduction of pollutant emission [10].

Furthermore, the assumed electricity consumption of the station is much lower than the electric power generated by the PVGS. Accordingly, with the integration of the PVGS on the distribution system, the power flow of distribution system will be changed with the PV generation as well as the loading level of each bus. The power loss reduction that resulted from the power injection of the PVGS can be estimated by executing the distribution load flow analysis. The voltage variation of the practical distribution feeder due to PV generation is solved to determine the maximum PVGS penetration allowed without causing the violation of system operation constraints.

The paper is organized as follows. First, Section 2 presents the methodology of this research followed by the case study simulation results presented in Section 3. A brief introduction of PUB DNST network topology in a one-line diagram including its daily load demand is also shown in Section 3. Section 4 presents the financial analysis scheme followed by a conclusion in Section 5 .

\section{PVGS Feasibility Study Methodology}

To evaluate the maximum installation capacity of PVGS without causing voltage violation, the load flow analysis is applied to solve the system voltage and power loss according to the hourly feeder loading and solar irradiation. After that, the cost-benefit analysis based on the NPV method from utility point of view is executed to know its effectiveness on energy saving. Figure 1 shows the flowchart of the proposed methodology. It is further described as the following steps.

Step 1 prepares the study system configuration and data for load flow analysis. The study network configuration should be identified for preparing a one-line diagram. By the way, the line segment attributes such as conductor size and length and distribution transformer capacity and impedance are also collected at the same time. It is also necessary to retrieve the hourly power generation and loading of the study system.

Step 2 is to find the maximum allowable installation capacity at the proposed installation site. It needs to execute 24-hour load flow analysis with and without considering the installation of PVGS. The output power of PVGS is assumed to be at its peak rating capacity during the load flow analysis. The simulation results for the voltage at all buses and power generation of each generation unit must be examined in order not to violate the limits. In this paper, all the buses voltage should be controlled within $0.95-1.05$ p.u and the generator output power should be operated within 0.3-1.0 times of its rating capacity. In addition, the allowable voltage variation ratio (VVR) at all buses is limited within $\pm 5 \%$ to ensure power quality. And the VVR can be defined as

$$
\operatorname{VVR}_{k}(\%)=\frac{V_{k}^{\mathrm{PVGS}}-V_{k}}{V_{k}} \times 100 \%,
$$

where $V_{k}$ and $V_{k}^{\mathrm{PVGS}}$ are the voltage magnitude at bus $k$ without and with PVGS, respectively.

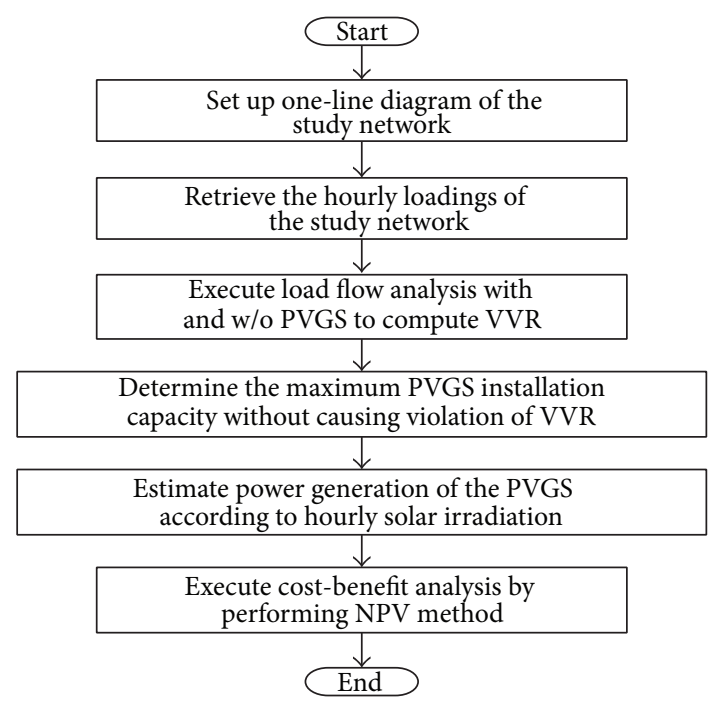

FIGURE 1: Flowchart of the proposed PVGS feasibility study methodology.

By executing the proposed methodology, the maximum PVGS installation is therefore obtained without violating the limits. By the way, the penetration level (PL) of renewable energy on the power system can be defined as

$$
\mathrm{PL}(\%)=\frac{\sum_{i} P_{\mathrm{PV}}^{i}}{P_{\text {total }}} \times 100 \%,
$$

where $P_{\mathrm{PV}}^{i}$ is the rating capacity of the $i$ th PVGS and $P_{\text {total }}$ is the total power delivered to load.

Step 3 is used to estimate the power generation of PVGS. To make the analysis reasonable and able to be used in general case for varying solar irradiance condition, it is necessary to find out the mathematical model of the PVGS. In this paper, the PVGS model is obtained and verified by the actual system which has been installed at the Kaohsiung World Games Stadium in Taiwan [11]. The maximum power output of the PVGS is derived as (3), while the surface temperature $\left(T_{S}\right)$ of the PV panel is calculated as (4). Consider the following:

$$
\begin{gathered}
P_{\max }=-1.15 \times 10^{4}+909 G+754 T_{S}-2 G T_{S} \quad(\mathrm{~W}), \\
T_{S}=0.903+0.0014 G-1.39 \times 10^{-7} G^{2} \quad\left({ }^{\circ} \mathrm{C}\right),
\end{gathered}
$$

where $G$ is the solar irradiance $\left(\mathrm{W} / \mathrm{m}^{2}\right)$. Therefore here in order to obtain the estimated power generation of PVGS, an hourly real solar irradiation was used. After that, the 24-hour load flow is performed again to know the actual effectiveness of PVGS on the power system.

Step 4 executes cost-benefit analysis. A financial analysis for the proposed PVGS based on the expected power generation is also investigated in this paper to ensure the feasibility of the system in not only the engineering aspect but also the economic aspect. This procedure can figure out whether or not the capital investment cost of the large scale PVGS can be fully recovered from the annual fuel and power loss saving over the system life cycle. The cost-benefit analysis 


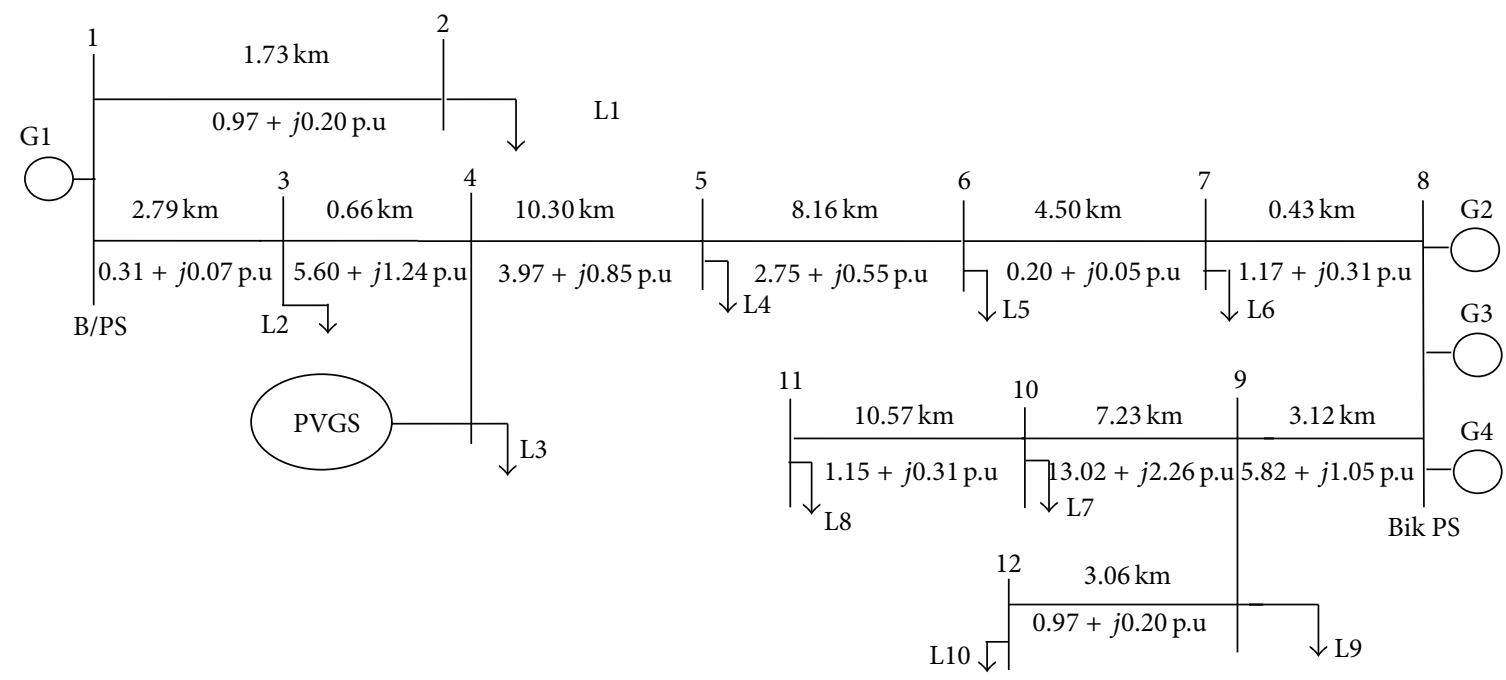

FIGURE 2: One-line diagram of the study of PUB DNST feeder.

adopts NPV and PBY method. The NPV of an investment is the sum of the present values of all cash flows such as capital investment and revenue generated over the life cycle. A project is considered to be financially feasible only if the corresponding NPV is positive. The NPV of the investment can be calculated by

$$
\mathrm{NPV}=-\mathrm{C}_{\mathrm{CI}}+\sum_{i=1}^{n} \mathrm{PWF}^{i} * \mathrm{CF}_{i}
$$

where $C_{\mathrm{CI}}$ is the capital investment cost of the PVGS and $\mathrm{PWF}^{i}$ and $\mathrm{CF}_{i}$ are the present worth factor and the net cash inflow for year $i$, respectively. $\mathrm{CF}_{i}$ can be further expressed as

$$
\mathrm{CF}_{i}=\left(C_{\mathrm{APLS}, i}+C_{\mathrm{AFS}, i}\right) *(1-\mathrm{dr})^{i}-C_{\mathrm{O} \& \mathrm{M}, i},
$$

where $C_{\mathrm{APLS}, i}$ and $C_{\mathrm{AFS}, i}$ are the annual power loss saving cost and fuel saving cost at year $i$. And dr is the PVGS performance derating rate and the $C_{\mathrm{O} \& \mathrm{M}, i}$ is the annual operation and maintenance cost at year $i$, respectively. $C_{\mathrm{APLS}, i}$ and $C_{\mathrm{AFS}, i}$ can be further expressed as

$$
\begin{aligned}
C_{\mathrm{APLS}, i}=\mathrm{CoE} *( & \mathrm{NSD}_{\mathrm{yr}} * \sum_{h=1}^{24}\left(X_{h}^{\mathrm{wpv}}-X_{h}^{\mathrm{pv}}\right) \\
& \left.+\mathrm{NCD}_{\mathrm{yr}} * \sum_{h=1}^{24}\left(X_{h}^{\mathrm{wpv}}-X_{h}^{\mathrm{pv}}\right)\right) \\
C_{\mathrm{AFS}, i}=\mathrm{Gpc} *( & \mathrm{NSD}_{\mathrm{yr}} * \sum_{h=1}^{24}\left(Y_{h}^{\mathrm{wpv}}-Y_{h}^{\mathrm{pv}}\right) \\
& \left.+\mathrm{NCD}_{\mathrm{yr}} * \sum_{h=1}^{24}\left(Y_{h}^{\mathrm{wpv}}-Y_{h}^{\mathrm{pv}}\right)\right)
\end{aligned}
$$

where $X_{h}^{\mathrm{wpv}}, X_{h}^{\mathrm{pv}}, Y_{h}^{\mathrm{wpv}}$, and $Y_{h}^{\mathrm{wpv}}$ are the PUB DNST's active power loss without PVGS, active power loss with PVGS, fuel consumed without PVGS, and fuel consumed with PVGS for an hour $h$, respectively; $\mathrm{NSD}_{\mathrm{yr}}$ and $\mathrm{NCD}_{\mathrm{yr}}$ are the total number of sunny and cloudy for the year yr, respectively; $\mathrm{CoE}$ and $\mathrm{Gpc}$ are the cost of energy and the generator's production cost, respectively.

By the way, the PBY can be obtained by setting the value of NPV to be zero in (5).

\section{Case Study: Electrical Power System Simulation}

To determine how large the PV projects can be put into effect at the proposed installation site without violating the voltage limits, a large scale PVGS installed at PUB DNST in Kiribati was selected as a case study for computer simulation. Besides, a financial analysis is also performed in the last section of this paper to justify whether this PV project investment is viable or not.

Figure 2 shows the one-line diagram of the power system in Kiribati. The large scale PVGS is assumed to be installed at Bus 4. The existing network configuration can be described in more detail as follows. There is one diesel generator at Betio (Bus 1) with the available capacity of $1200 \mathrm{~kW}$ and three diesel generators at Bikenibeu (Bus 8) with the available capacities of $1350 \mathrm{~kW}$ each, which provide a base load at specific fuel consumption of 0.25 litre/kWh. The rating generators output voltage is $11 \mathrm{kV}$ with an operating frequency of $50 \mathrm{~Hz}$. Approximately 60 underground cables with various types are used in distributing $11 \mathrm{kV}$ network around the island. There are 59 transformers in service, which are $11 \mathrm{kV} / 415 \mathrm{~V}$ step down transformers with rated capacity of 50,100, 200, and $750 \mathrm{kVA}$.

Figure 3 shows typical daily load profile that was recorded on South Tarawa. It shows basically two insights: firstly, the peak load is $3.2 \mathrm{MW}$, which occurred at $11 \mathrm{hrs}$ and $13 \mathrm{hrs}$; secondly, the off-peak load is $2 \mathrm{MW}$, which occurred from $5 \mathrm{hrs}$ to $6 \mathrm{hrs}$. This figure also obviously shows that the high power consumption on the island occurs significantly during 


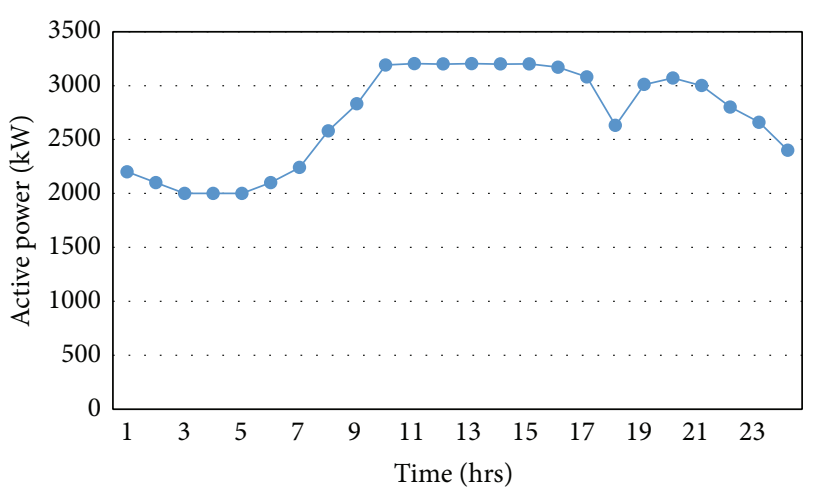

Figure 3: Typical daily load demand profile.

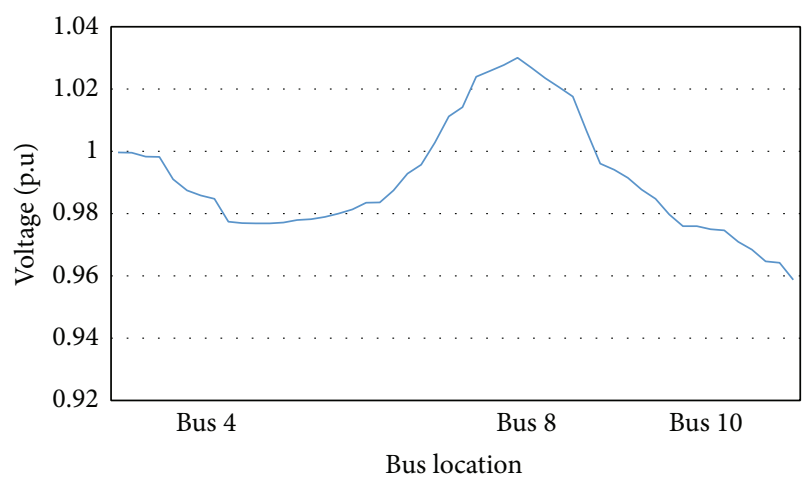

FIGURE 4: Voltage profile for utility sector without PVGS.

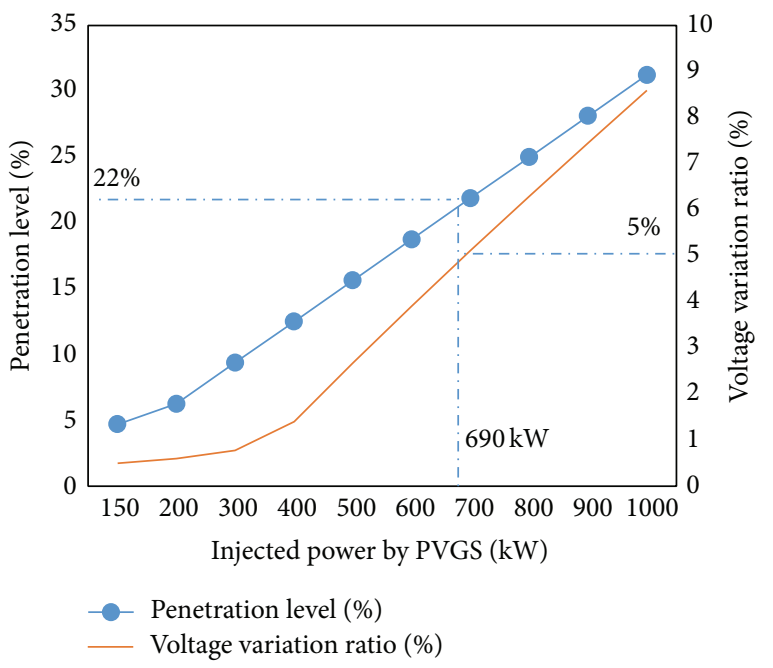

FIGURE 5: VVR and PL versus the injected power by PVGS.

working and business hours. In order to simplify the process of determining the annual load demand, it is assumed that all days throughout the year have the same load demands as shown in Figure 3. This assumption is based upon the fact that, in terms of the United Nation statistics, Kiribati is among the least developed countries in the world [12]. The profile

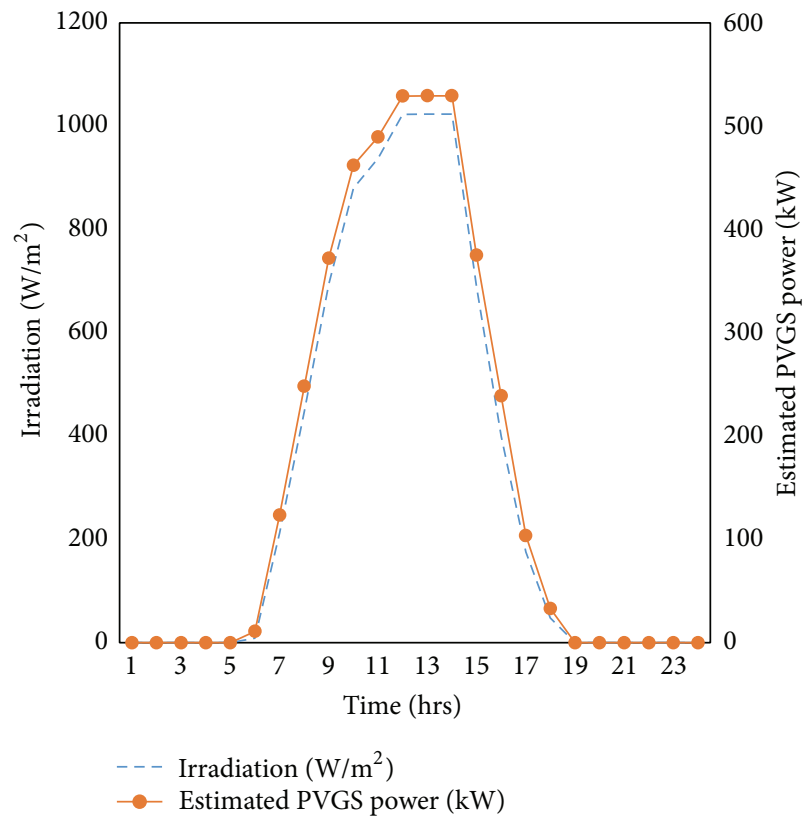

FIGURE 6: Daily solar irradiance and estimated PVGS power generation at sunny day.

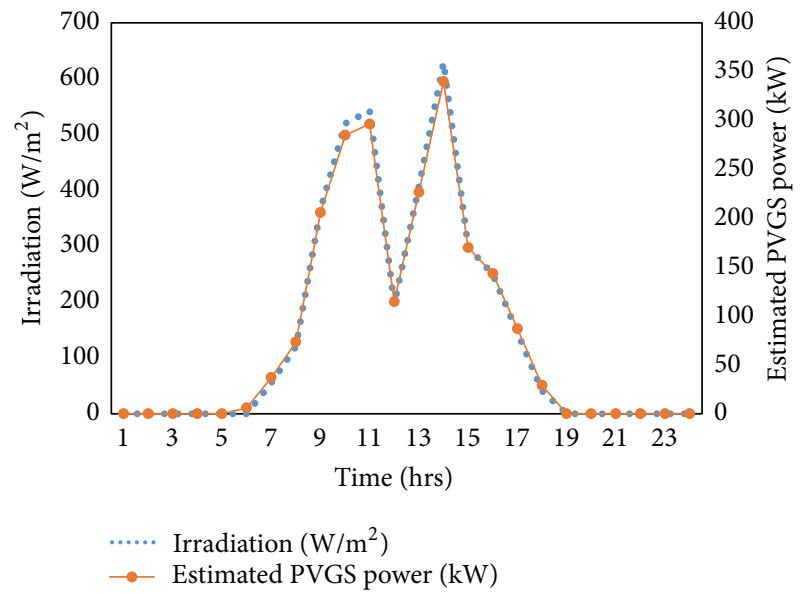

FIGURE 7: Daily solar irradiance and estimated PVGS power generation at cloudy day.

shows that the loading occurs during daytime, which implies that the power generation by the PV system can effectively offset Bus 4 feeder loading.

Based on the PUB DNST network topology and hourly loading, the load flow simulation results in Figure 4 show the voltage profile of the buses while regulating the voltage at G2-4 and G1 to 1.03 p.u. and 1.0 p.u., respectively. It is found that the voltages are varied between 0.956 p.u. and 1.03 p.u. in normal condition; these simulation results satisfy the voltage operation limits for providing well power quality to customers $[1,12]$.

Introducing the PVGS to the existing network may alter the voltage level at installation site (Bus 4) and nearby buses. 


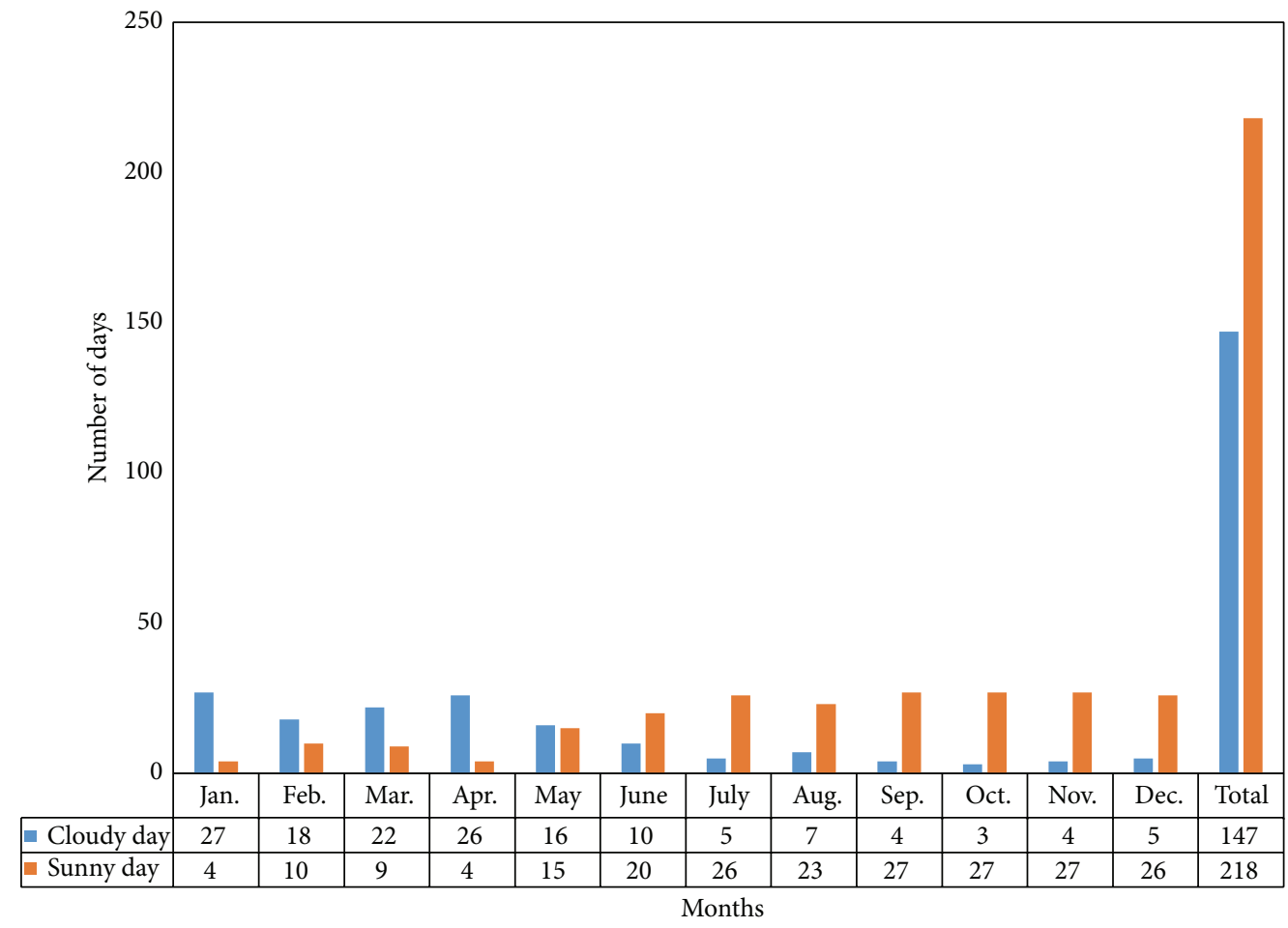

FIGURE 8: Monthly number of cloudy and sunny days for the year 2010.

In order to make sure the voltage level, at all buses, remains at required limits, the maximum allowed PVGS installation capacity will be taken into consideration. After applying the load flow analysis with different injected power of PVGS, it is found that the maximum allowable power at Bus 4 is $690 \mathrm{~kW}$ which corresponds to the penetration level of $22 \%$ as shown in Figure 5. This means that if PVGS installation capacity is larger than maximum allowable power, the penetration impact becomes more severe and may lead to overvoltage problem.

A sorting analysis of hourly weather data from Meteorology Office in Kiribati was performed to derive the sunny and cloudy duration curve of solar irradiation analysis. Figures 6 and 7 show recorded solar irradiation with simulated daily estimated PVGS generation for sunny and cloudy day, respectively. According to the weather information, a sunny day had sunshine duration of 13 hours in March 2010. With this solar irradiation condition, it is found that the estimated generation power for a $690 \mathrm{kWp}$ PVGS is increased with the solar irradiation by applying the model at (3) and (4). The maximum power generation is $530 \mathrm{~kW}$ and occurs at $12 \mathrm{hrs}$. Also, a cloudy day has low solar irradiation and the maximum $\mathrm{PV}$ power generation is $340 \mathrm{~kW}$ at $14: 30 \mathrm{pm}$. It is also found that the PV generation power fluctuates dramatically between 10:00 am and 14:00 pm due to the cloudy effect during the daytime period. A historical weather data provided by Meteorology Office in 2010 as presented in Figure 8 shows the monthly number of cloudy and sunny day, respectively. Besides, it also shows the total number of sunny and cloudy days in a year, respectively, that is, $218\left(\mathrm{NSD}_{2010}\right)$ and 147

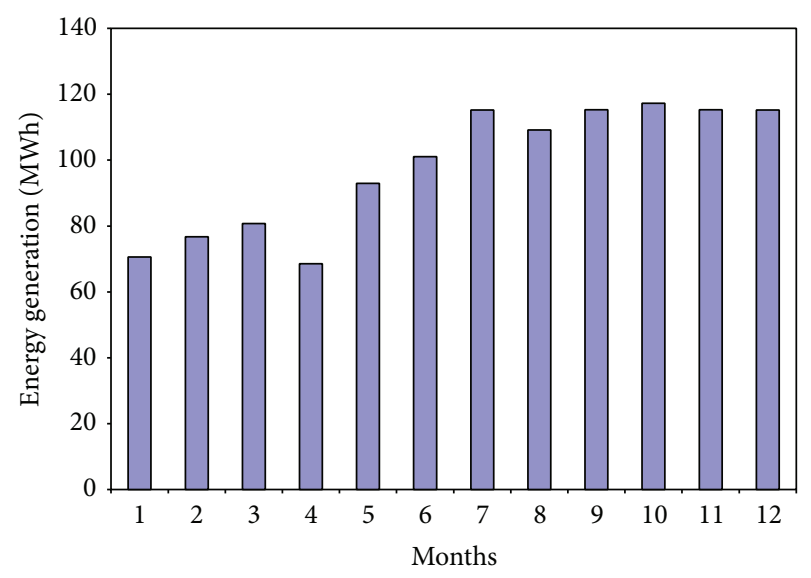

FIGURE 9: Annual energy generation from PVGS.

$\left(\mathrm{NSD}_{2010}\right)$. In order to simplify the process of determining the annual PV power generation, it is assumed that all sunny days have the same sunny solar irradiation condition and all cloudy days have the same cloudy solar irradiation condition throughout the year. With this assumption a yearly PVGS contribution when the PVGS capacity of $690 \mathrm{kWp}$ was installed at Bus 4 has been shown in Figure 9. A calculated result shows that, with the aforementioned PVGS capacity, an estimated total energy produced annually is $1178.14 \mathrm{MWh}$.

To perform 24-hour load flow simulation for proving the feasibility of the PVGS, existing network information and 


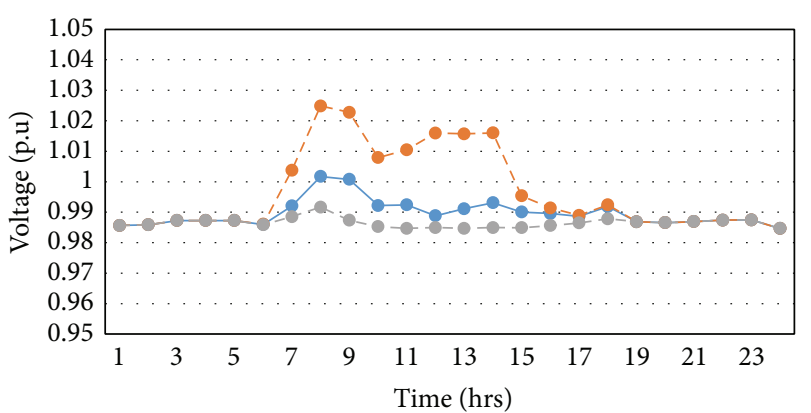

$\rightarrow$ With PVGS (cloudy day)

- - With PVGS (sunny day)

- - Without PVGS

FIGURE 10: Voltage profile at Bus 4 with and without PVGS.

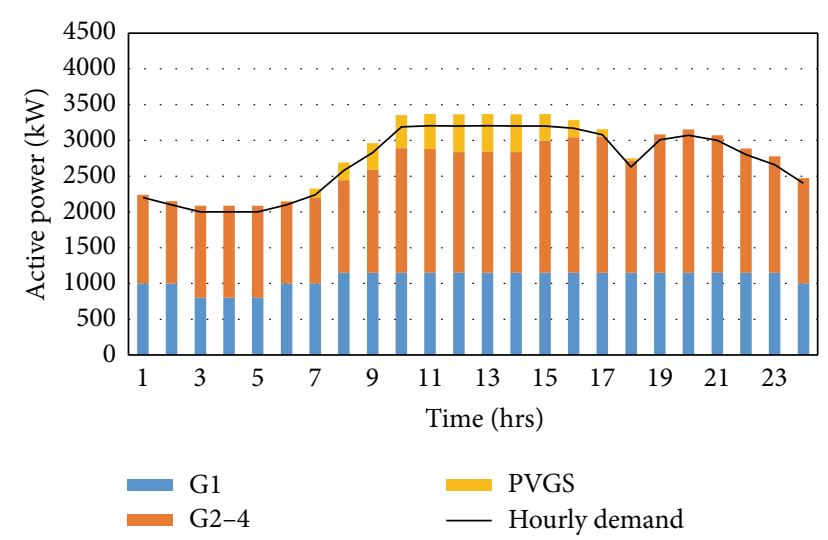

FIGURE 11: Hourly power generation and load demand for sunny day.

hourly estimated PVGS injected power are both included in the MatLab power program. Figure 10 shows hourly voltage profile at Bus 4 with and without considering the proposed $690 \mathrm{kWp}$ PVGS. It is observed that the voltage fluctuation becomes larger due to PVGS power injection during daytime. For example, at 8:00 am the voltage level rises from $0.994 \mathrm{p} . \mathrm{u}$ to 1.025 p.u and the VVR is $3.12 \%$ for a sunny day. However, the voltage level and VVR of all buses are all within the acceptable range since the estimated PVGS power generation is less than the maximum installation capacity. Figures 11 and 12 show the hourly power generationand load demand for typical sunny day and cloudy day, respectively. Meanwhile, the corresponding hourly losses are shown in Figure 13. Without the PVGS, the highest loss of $178 \mathrm{~kW}$ occurs from 11:00 am to $15: 00 \mathrm{pm}$ and the lowest network loss of $39 \mathrm{~kW}$ occurs at 1:00 am, respectively. With the PVGS, the network loss fluctuated starting from $6: 00 \mathrm{am}$ to $18: 00 \mathrm{pm}$ and is reduced mostly due to the power injection of PVGS. In Kiribati, diesel generator usually consumes 0.25 litre of fuel at price of $\$ 0.75 /$ liter to produce $1 \mathrm{kWh}$. It means the production cost is $0.1875 \mathrm{c} / \mathrm{kWh}$. Therefore the estimated hourly fuel consumption cost is as shown in Figure 14. It is also found

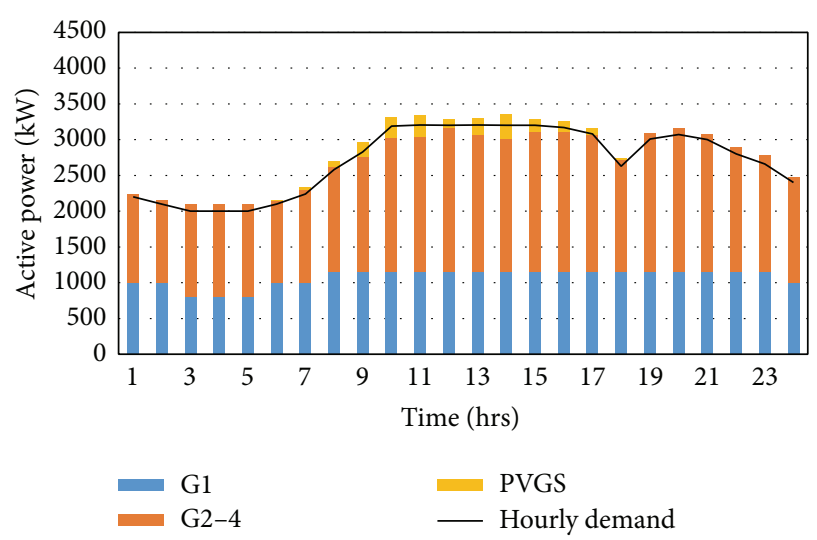

FIGURE 12: Hourly power generation and load demand for cloudy day.

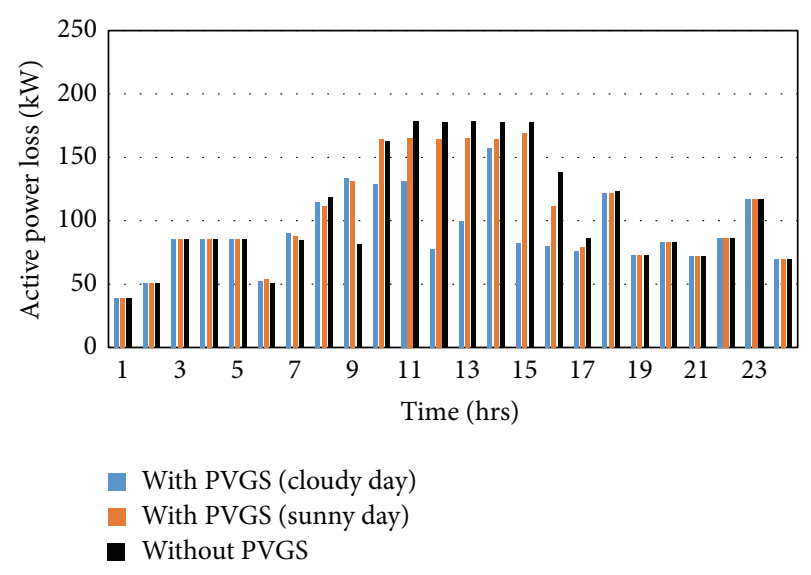

FIGURE 13: Hourly feeder losses with and without PVGS.

that the daily fuel cost is reduced from US $\$ 4,630,180$ to US $\$ 167,246$ for a sunny day and to US\$66,258 for a cloudy day if the proposed PVGS is installed.

\section{Case Study: Financial Analysis}

This section executed the financial analysis of a large scale $\mathrm{PV}$ investment project in a small island. The purpose of this scenario is to analyze how much benefit that PUB DNST may take from installation of the proposed PVGS system. Thanks to the benefit of power loss reduction and fuel saving that resulted from PVGS contribution described in Section 3, the monthly trend of fuel cost with and without PVGS is presented in Figure 15. Calculated results by (8) show that fuel cost saving for 218 sunny days in the year 2010 is US $\$ 167246$, while for 147 cloudy days left the value is US\$66,258. Thus, annual fuel saving cost $\left(C_{\mathrm{AFS}}\right)$ due to the PVGS is US $\$ 233,505$, while annual fuel cost without the PVGS is US $\$ 4630180$. Figure 16 shows the trend of network losses with and without PVGS system on PUB DNST. It is found that the annual network distribution loss has been reduced from $944 \mathrm{MW}$ to $876 \mathrm{MW}$ due to PVGS. Based on this, it may have an energy 


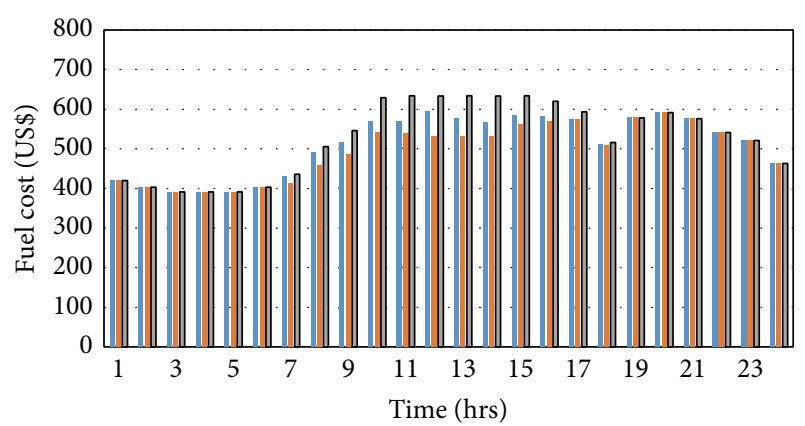

- With PVGS (cloudy day)

With PVGS (sunny day)

$\square$ Without PVGS

FIGURE 14: Hourly fuel cost with and without PVGS.

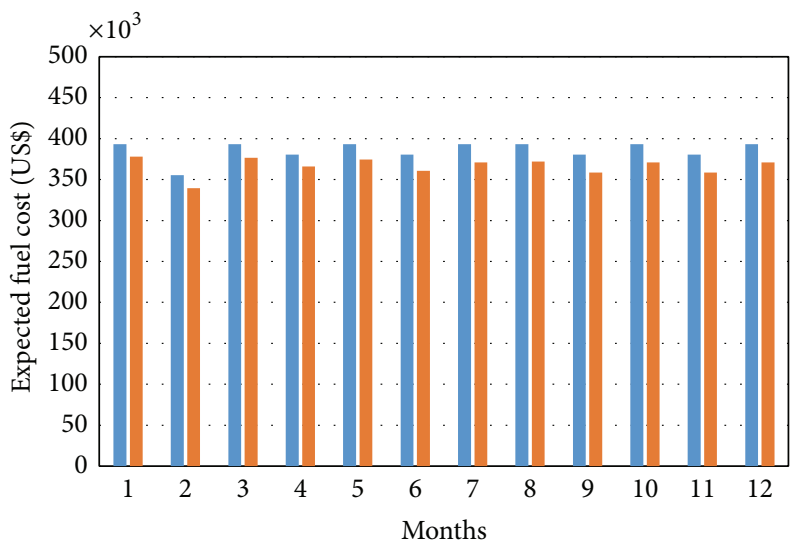

Without PVGS

With PVGS

FIGURE 15: Monthly fuel cost with and without PVGS.

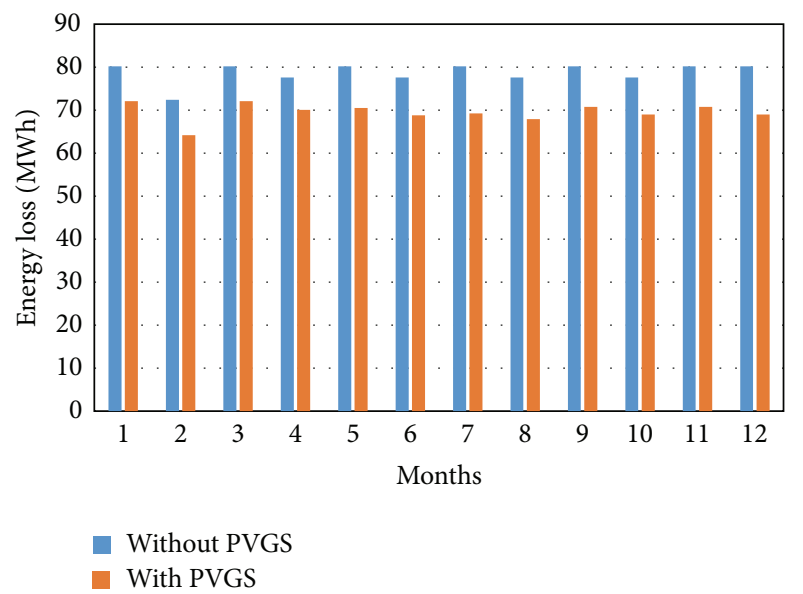

Figure 16: Monthly energy losses with and without PVGS.
TABLE 1: Parameters of the financial evaluation.

\begin{tabular}{lc}
\hline Items & Parameters \\
\hline PWF & 0.98039 \\
Life cycle (year) & 25 \\
Annual O\&M cost (\$) & 16,172 \\
PVGS's performance derating rate (\%) & 1.4 \\
Capital investment cost (\$) & $2,299,770$ \\
Annual power loss saving cost $(\$)$ & 26,800 \\
Annual fuel saving cost $(\$)$ & 233,505 \\
\hline
\end{tabular}

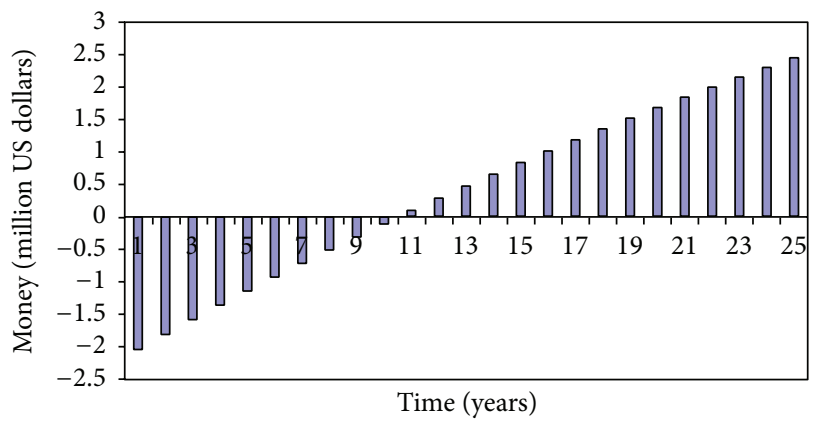

FIGURE 17: Net present value for installation capacity of $690 \mathrm{kWp}$ PVGS.

loss saving of $67 \mathrm{MWh}$ annually. Consequently, calculating result by (7) with the cost of energy $(\mathrm{CoE})$ of $0.40 \mathrm{c} / \mathrm{kWh}$ in Kiribati, the energy loss saving cost is US $\$ 26,800$. Thus, due to the power injected by the PVGS to the power system, PUB may earn power loss saving cost $\left(C_{\mathrm{APLS}}\right)$ of US $\$ 26,800$ annually.

Financial parameters used in this paper to calculate the estimated benefit from the PVGS are shown in Table 1. The present worth factor (PWF) is 0.98093 in the 25 years evaluation period. And the capital investment cost and annual O\&M cost are US\$2,299,700 and US\$16172, respectively. Based on the saving derived due to the PVGS contribution, Table 1 shows the PVGS capital investment cost, which obviously is the present worth of spending for this year, that is, US $\$ 2,299,700$. With the aforementioned PVGS capital investment (or present worth spending) and the present worth of saving for the next 11 years, derived in Table 2, combined, the NPV is a positive value, that is, $\$ 89,492$. Thus the PVGS capital investment cost is more than justified by the continuing saving in losses and fuel consumption. Since the $\mathrm{NPV}=0$, then the evaluation is feasible. Here in Figure 17 it is shown that the PBY and the NPV over the entire PVGS lifetime are 11 years and $\$ 2,466,424$, respectively.

\section{Conclusions}

A large scale PV installation capacity has been analyzed both technically and economically on a small island distribution feeder to justify whether the PVGS investment is feasible or not from the utility sector's point of view. With the proposed 
TABLE 2: Simulation results of NPV.

\begin{tabular}{|c|c|c|c|c|c|}
\hline Year $(i)$ & PWF & $(1-\mathrm{dr})^{i}$ & Saving at present (\$) & Accumulated (\$) & NPV (\$) \\
\hline 1 & 0.98 & 0.98 & $239,345.55$ & $239,345.55$ & $-2,060,424.45$ \\
\hline 2 & 0.96 & 0.97 & $234,651.99$ & $473,997.54$ & $-1,825,772.46$ \\
\hline 3 & 0.94 & 0.95 & $230,050.46$ & $704,048.00$ & $-1,595,722.00$ \\
\hline 4 & 0.92 & 0.94 & $225,539.17$ & $929,587.17$ & $-1,370,182.83$ \\
\hline 5 & 0.91 & 0.93 & $221,116.35$ & $1,150,703.52$ & $-1,149,066.48$ \\
\hline 6 & 0.89 & 0.91 & $216,780.26$ & $1,367,483.77$ & $-932,286.23$ \\
\hline 7 & 0.87 & 0.90 & $212,529.20$ & $1,580,012.97$ & $-719,757.03$ \\
\hline 8 & 0.85 & 0.89 & $208,361.50$ & $1,788,374.46$ & $-511,395.54$ \\
\hline 9 & 0.84 & 0.88 & $204,275.53$ & $1,992,649.99$ & $-307,120.01$ \\
\hline 10 & 0.82 & 0.86 & $200,269.69$ & $2,192,919.68$ & $-106,850.32$ \\
\hline 11 & 0.80 & 0.85 & $196,342.40$ & $2,389,262.08$ & $89,492.08$ \\
\hline 12 & 0.79 & 0.84 & $192,492.12$ & $2,581,754.20$ & $281,984.20$ \\
\hline 13 & 0.77 & 0.83 & $188,717.35$ & $2,770,471.55$ & $470,701.55$ \\
\hline 14 & 0.76 & 0.82 & $185,016.60$ & $2,955,488.15$ & $655,718.15$ \\
\hline 15 & 0.74 & 0.80 & $181,388.43$ & $3,136,876.58$ & $837,106.58$ \\
\hline 16 & 0.73 & 0.79 & $177,831.40$ & $3,314,707.99$ & $1,014,937.99$ \\
\hline 17 & 0.71 & 0.78 & $174,344.13$ & $3,489,052.11$ & $1,189,282.11$ \\
\hline 18 & 0.70 & 0.77 & $170,925.24$ & $3,659,977.35$ & $1,360,207.35$ \\
\hline 19 & 0.69 & 0.76 & $167,573.40$ & $3,827,550.75$ & $1,527,780.75$ \\
\hline 20 & 0.67 & 0.75 & $164,287.28$ & $3,991,838.03$ & $1,692,068.03$ \\
\hline 21 & 0.66 & 0.74 & $161,065.61$ & $4,152,903.64$ & $1,853,133.64$ \\
\hline 22 & 0.65 & 0.73 & $157,907.11$ & $4,310,810.75$ & $2,011,040.75$ \\
\hline 23 & 0.63 & 0.72 & $154,810.55$ & $4,465,621.30$ & $2,165,851.30$ \\
\hline 24 & 0.62 & 0.71 & $151,774.72$ & $4,617,396.02$ & $2,317,626.02$ \\
\hline 25 & 0.61 & 0.70 & $148,798.42$ & $4,766,194.44$ & $2,466,424.44$ \\
\hline
\end{tabular}

installation site, it is found that maximum allowable power of the PVGS of $690 \mathrm{kWp}$ may fit the voltage variation ratio limit of $5 \%$. According to the hourly solar irradiation and temperature, the estimated power generation of PVGS is applied to execute the 24-hour load flow in a sunny day and cloudy day. It is found that the annual fuel saving of 311,333 litre and energy losses saving of $67 \mathrm{MWh}$ are obtained due to the installation of PVGS. After that, a cost-benefit analysis is performed and it takes 11 years to recover the initial capital cost. In addition, the NPV over its entire life cycle is around $\$ 2.47$ million. This amount of NPV obtained in the 25-year period is sufficient enough to improve the utility sector in terms of cash flow injection to improve utility sector's annual internal operation cost or to allocate funding for the development of other essential renewable projects to achieve sustainable environment that in turn benefits the utility and the country as a whole.

\section{Conflict of Interests}

The authors declare that there is no conflict of interests regarding the publication of this paper.

\section{Acknowledgment}

This work is supported by the MOST of Taiwan (MOST 1033113-E-214-002).

\section{References}

[1] C. H. Lin, W. L. Hsieh, C. S. Chen, C. T. Hsu, and T. T. $\mathrm{Ku}$, "Optimization of photovoltaic penetration in distribution systems considering annual duration curve of solar irradiation," IEEE Transactions on Power Systems, vol. 27, no. 2, pp. 10901097, 2012.

[2] “Kiribati Infrastructure Sector Review," http://www.theprif.org/ sites/theprif.org/files/Final\%20Kiribati\%20Infrastructure \%20Sector\%20Review.pdf.

[3] "Kiribati Climate Change," http://www.climate.gov.ki/2013/03/ 26/new-solar-project-for-south-tarawa/.

[4] B. Chabot, "From costs to prices: economic analysis of photovoltaic energy and services," Progress in Photovoltaics: Research and Applications, vol. 6, no. 1, pp. 55-68, 1998.

[5] G. Nofuentes, J. Armilera, and F. J. Muñoz, "Tools for the profitability analysis of grid-connected photovoltaic," Progress in Photovoltaics: Research and Applications, vol. 10, no. 8, pp. 555-570, 2002.

[6] D. J. Swider, L. Beurskens, S. Davidson et al., "Conditions and costs for renewables electricity grid connection: examples in Europe," Renewable Energy, vol. 33, no. 8, pp. 1832-1842, 2008.

[7] A. Roque, N. Fontes, J. Maia, C. Casimiro, and D. M. Sousa, "Economic aspects of a domestic micro-generation system," in Proceedings of the 2009 6th International Conference on the European Energy Market (EEM '09), Leuven, Belgium, May 2009. 
[8] D. L. Talavera, G. Nofuentes, J. Aguilera, and M. Fuentes, "Tables for the estimation of the internal rate of return of photovoltaic grid-connected systems," Renewable and Sustainable Energy Reviews, vol. 11, no. 3, pp. 447-466, 2007.

[9] G. Nofuentes, J. Aguilera, C. Rus, and R. L. Santiago, "A short assessment on the profitability of PV grid-connected systems using classical investment project analysis," in Proceddings of the 3rd World Conference on Photovoltaic Energy Conversion, pp. 2632-2635, Osaka, Japan, May 2003.

[10] J. L. Bernal-Agustín and R. Dufo-López, "Economical and environmental analysis of grid connected photovoltaic systems in Spain," Renewable Energy, vol. 31, no. 8, pp. 1107-1128, 2006.

[11] C. H. Lin, W. L. Hsieh, C. S. Chen, C. T. Hsu, T. T. Ku, and C. T. Tsai, "Financial analysis of a large-scale photovoltaic system and its impact on distribution feeders," IEEE Transactions on Industry Applications, vol. 47, no. 4, pp. 1884-1891, 2011.

[12] "Least Developed Countries Factsheet," https://www.un.org/en/ development/desa/policy/cdp/ldc/profile/country_100.shtml. 

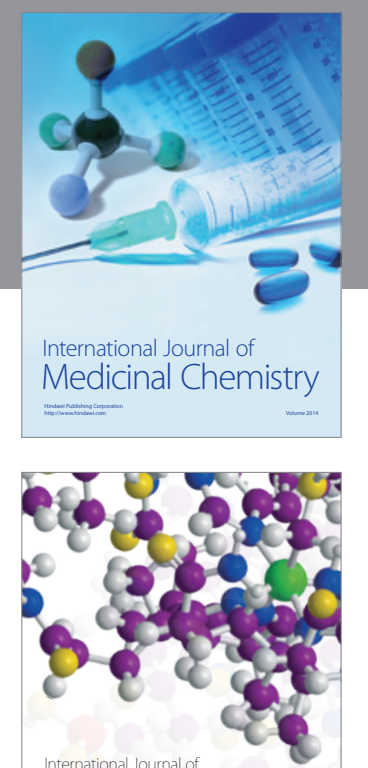

\section{Carbohydrate} Chemistry

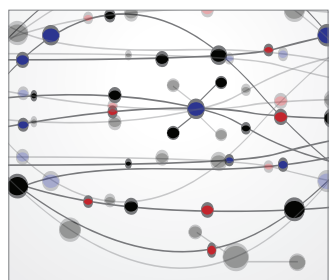

The Scientific World Journal
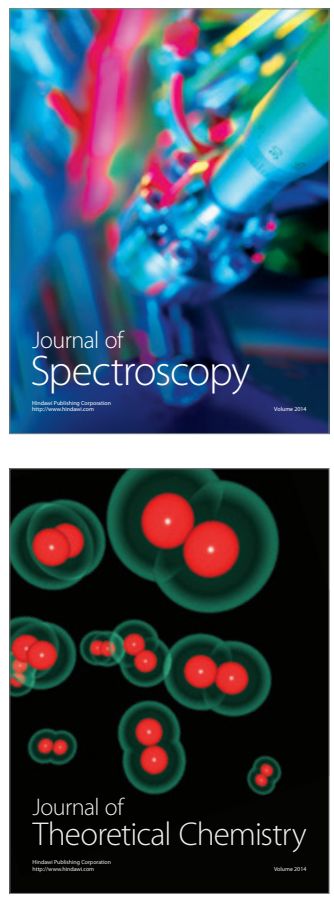
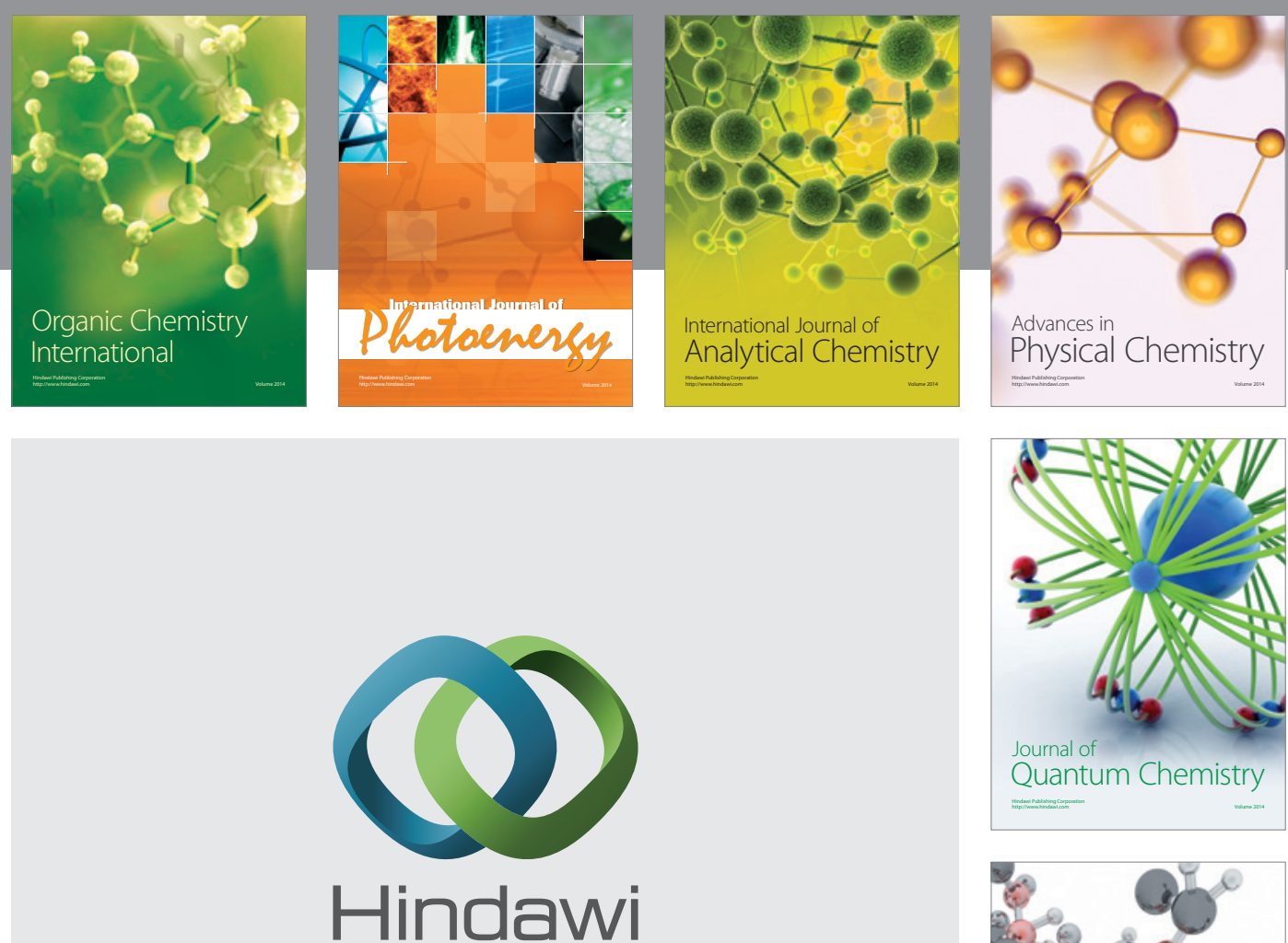

Submit your manuscripts at

http://www.hindawi.com

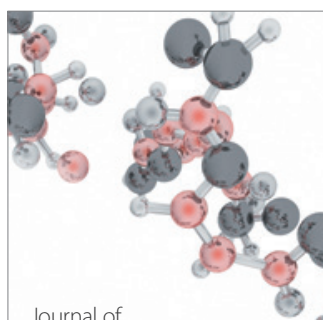

Analytical Methods

in Chemistry

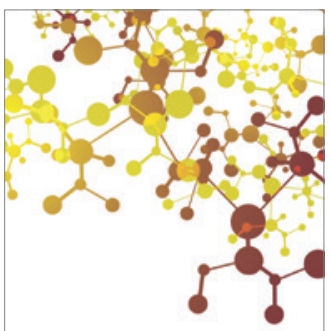

Journal of

Applied Chemistry

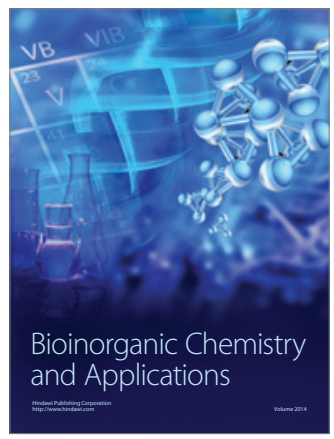

Inorganic Chemistry
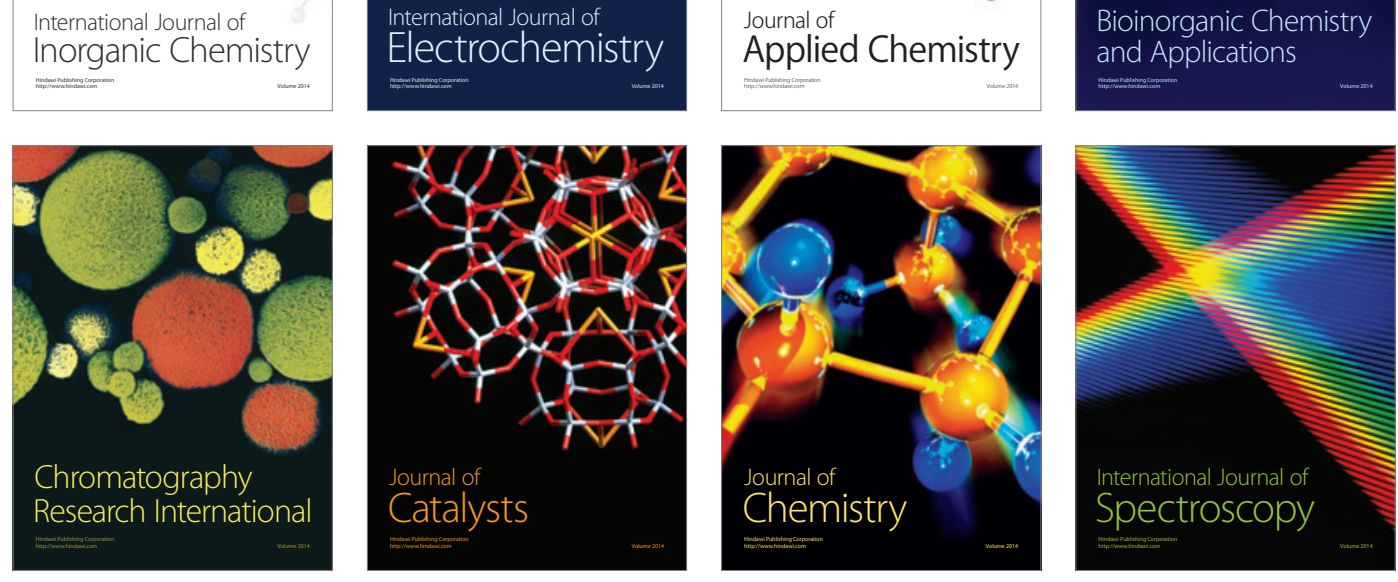